\title{
(Paper No. 1773.)
}

\section{"Imperial Government Railways of Japan.-The Osaka- yama Tunnel, Otzu, Lake Biwa."}

By Thomas Manson Rymer-Jones, M. Inst. C.E.

The Osakayama tunnel is situated on that portion of the line which has been extended from Kioto to Otzu, a distance of about 10 miles. This line was designed, surveyed and laid out by Mr. T. R. Shervinton, M. Inst. C.F., the principal engineer when the works were carried out. The length includes $5 \frac{1}{2}$ miles of gradients of 1 in 40 .

The Osakayama tunnel is 727 yards in length; the width at the springing of the arch is 14 feet, and the height from rail level to the soffit of the arch is 14 feet; the gauge of the line is 3 feet 6 inches. The centre of the line was carried over the summit of the hill, and projected on to hills facing the entrances of the tunnel; from these points a plumb-bob at each entrance and a mark at some distance from it were lined in, the mark being so placed that both it and the plumb-bob were always visible, as the headings progressed, being put at an incline of 1 in 40 to correspond with the gradient of the tunnel.

No machinery was used. Two of Jordan's rock drills were provided, and the workmen tanght to use them; but the rock being at first soft and much broken they preferred working by hand. The whole of the excavation was therefore done by chisel and pick, with occasional hand-drilling for blasting purposes. The inclination of the line through the tunnel was 1 in 40 , the direction being from west to east. The tunnel was worked from each end by a heading at the level of the springing. No shafts wore used, as the shortest would have been 200 feet long. The headings were 6 feet by 5 feet.

The eastern heading was commenced on the 1st of October, 1878. In this heading little water was met with, and that little passed off easily down the incline. The western heading was worked day and night continuously; less timber was required for it owing to the rock being harder. This rock was, however, intersected by small clay veins which rendered it liable to fall in masses of a dangerous size. Owing to the falling gradient the water had to be pumped up; the quantity was not great. The pumps were made from large bamboos with a cross-handled plunger, and were worked in short lifts.

Following the headings, the excavation was carried on to the 
full dimensions. The arching, of two rings or four rings of bi ick, was turned throughout, except in a short length of treacherous ground, where six rings were used. The arching was underpinned with side walls 1 foot 6 inches thick on the entire north side; on the sonthern side for nearly the whole length the side walls were 4 lineal feet of wall 1 foot 6 inches thick, and 6 lineal feet of wall 9 inches thick, alternately. Old 15 -feet centres, with a rise of 5 feet 6 inches, which had been used for the bridges on the line below, were employed; two longitudinal beams and a transverse beam being added with the wedges to make up the difference between 5 feet 6 inches and 7 feet 9 inches, the inside radius of the arch when there were only two rings of brick. A smaller centre on the same principle was used where four rings were necessary, the radius then being 7 feet. By this method the top part of the centres was small enough when lowered to be passed ahead easily, and was found handy as well as cheap.

Ventilation was kept up by fans working at the end of long air-tubes of wood within closed doors at stated points, the air being passed through the drainage water for the sake of coolness.

No European superintendence was employed with the exception of the district engineer. The immediate charge of the work was in the hands of Mr. Kunisawa Yoshinaga, a Japanese engineer cadet, educated on the railway works below.

Only one accident occurred, due to the fall of some loose rock while shifting struts in a careless manner, whereby three labourers and a miner were killed. This fall delayed the east heading slightly.

The headings met, the lines and levels being correct, on the $10 \mathrm{ch}$ of September, 1879 ; the brickwork was completed on the 1st of June, 1880 ; the first engine passed through the tunnel on the 26 th of June, 1880 ; and the line was opened for traffic by the Mikado on the 14th of July, 1880.

The cost was:-

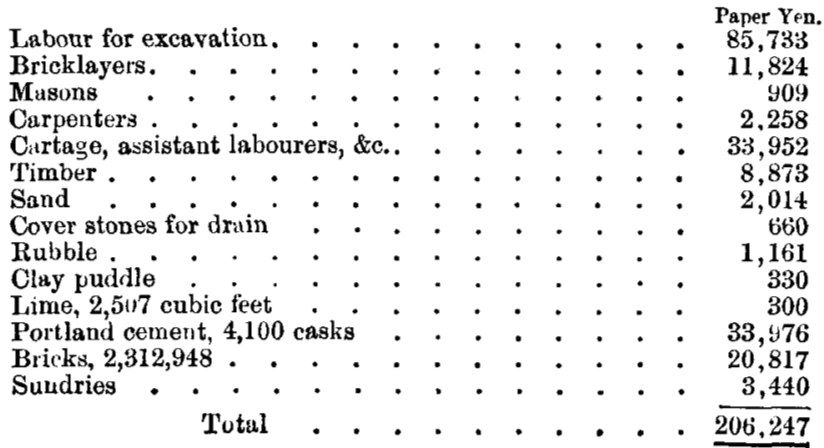


318 RYMER-JONES ON THE OSAKAYAMA RAILWAY TONNEL. [Selected

This, with the exchange at $3 s .10 d$. per dollar or yen, and 15 per cent. less for paper-money (as it was at the time, though now 75 per cent. discount, Nov. 1880), gives a total cost of $£ 34,37410$.

The wages paid were:-

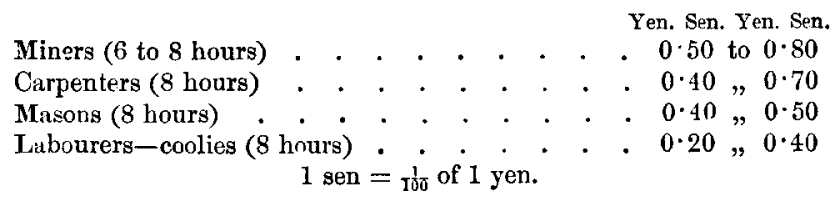

The number of miners employed was :-

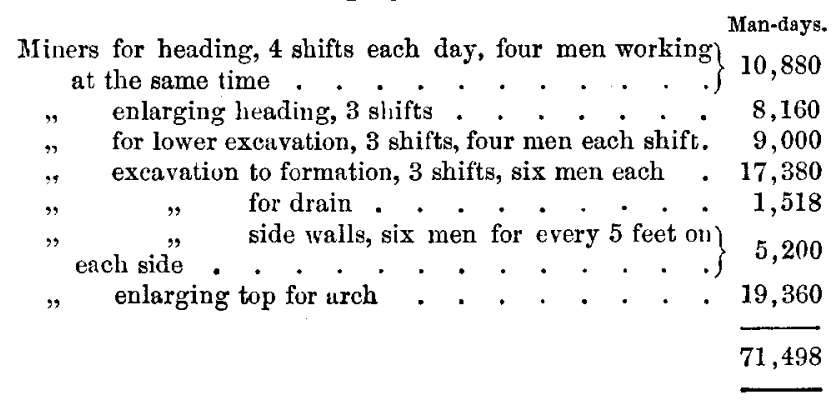

This account of cost and labour has been compiled from details supplied by the Japanese officials, and is calculated on daily a verages, small delays not being included. 